\title{
Evaluation of Fiber Bragg Grating and Distributed Optical Fiber Temperature Sensors
}

K. M. McCary

April 2017

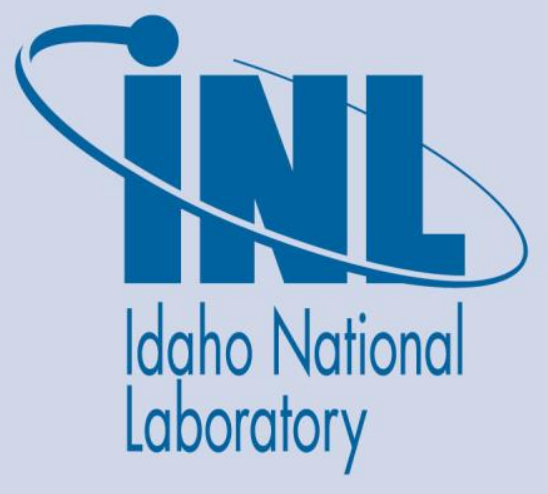

The INL is a U.S. Department of Energy National Laboratory operated by Battelle Energy Alliance 


\section{DISCLAIMER}

This information was prepared as an account of work sponsored by an agency of the U.S. Government. Neither the U.S. Government nor any agency thereof, nor any of their employees, makes any warranty, expressed or implied, or assumes any legal liability or responsibility for the accuracy, completeness, or usefulness, of any information, apparatus, product, or process disclosed, or represents that its use would not infringe privately owned rights. References herein to any specific commercial product, process, or service by trade name, trade mark, manufacturer, or otherwise, does not necessarily constitute or imply its endorsement, recommendation, or favoring by the U.S. Government or any agency thereof. The views and opinions of authors expressed herein do not necessarily state or reflect those of the U.S. Government or any agency thereof. 


\title{
Evaluation of Fiber Bragg Grating and Distributed Optical Fiber Temperature Sensors
}

\author{
K. M. McCary
}

April 2017

Idaho National Laboratory Idaho Falls, Idaho 83415

http://www.inl.gov

Prepared for the

U.S. Department of Energy

Office of Nuclear Energy

Under DOE Idaho Operations Office

Contract DE-AC07-05ID14517 



\section{Evaluation of Fiber Bragg Grating and Distributed Optical Fiber Temperature Sensors}

INL/EXT-17-41728

APRIL 2017

Approved by:

KURT DAVIS (Affiliate)

Name: Kurt L. Davis
Digitally signed by KURT DAVIS (Affiliate) Date: 2018.03.27 08:04:43 -06'00'

Date

Daw, Joshua E (DAWJE) $\begin{aligned} & \text { Digitally signed by Daw, Joshua E } \\ & \text { Date: 2018.03.27 08:43:22 -06'00' }\end{aligned}$

Name: Josh E. Daw

Date 


\section{SUMMARY}

Fiber optic temperature sensors were evaluated in the High Temperature Test Lab (HTTL) to determine the accuracy of the measurements at various temperatures. A distributed temperature sensor was evaluated up to $550^{\circ} \mathrm{C}$ and a fiber Bragg grating sensor was evaluated up to $750^{\circ} \mathrm{C}$. HTTL measurements indicate that there is a drift in fiber Bragg sensor over time of approximately $10^{\circ} \mathrm{C}$ with higher accuracy at temperatures above $300^{\circ} \mathrm{C}$. The distributed sensor produced some bad data points at and above $500^{\circ} \mathrm{C}$ but produced measurements with less than $2 \%$ error at increasing temperatures up to $400^{\circ} \mathrm{C}$ 


\section{CONTENTS}

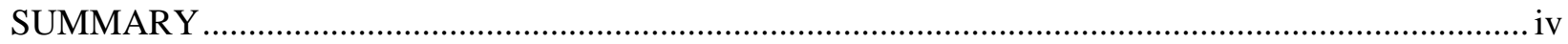

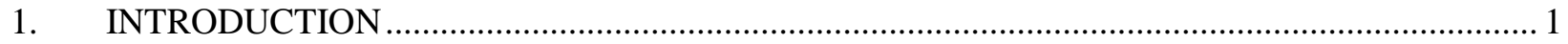

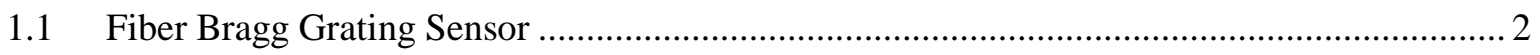

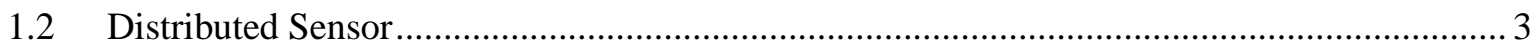

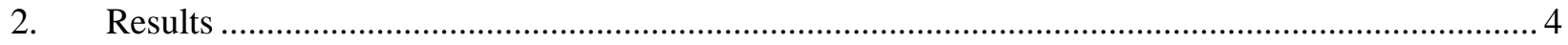

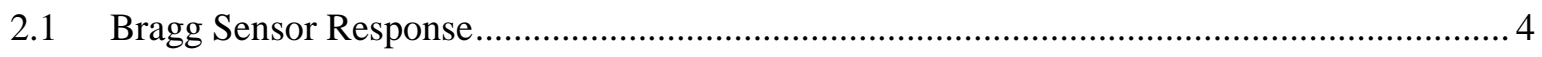

2.2 Distributed Sensor Response .................................................................................. 7

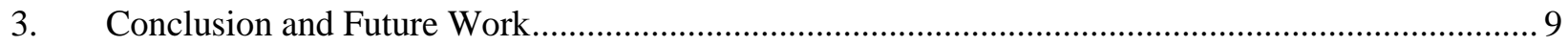

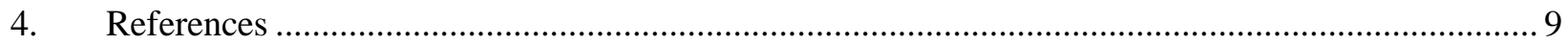

\section{FIGURES}

Figure 1. Trans Temp tube furnace by Thermcraft............................................................................ 1

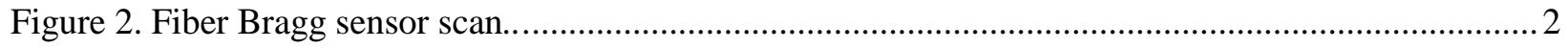

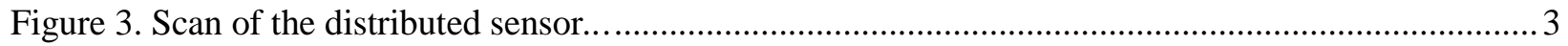

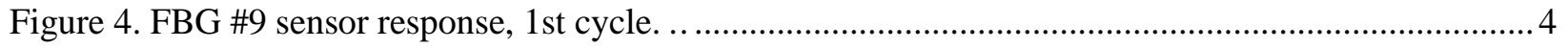

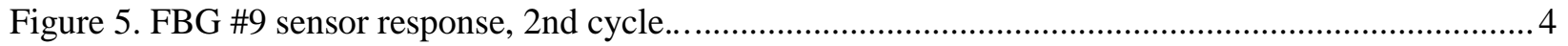

Figure 6. Sensor drift between the 1st cycle and the 2nd cycle of FBG \#9 ......................................... 6

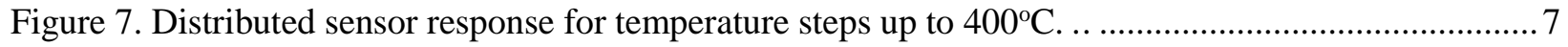

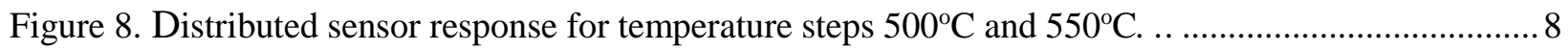

\section{TABLES}

Table 1. Temperature steps for the fiber Bragg grating and distributed sensors. .................................... 1

Table 2. Average Temperatures for FBG \#9 during the 1st run. ..........................................................5

Table 3. Average temperatures for FBG \#9 during the 2nd run. ..........................................................5

Table 4. Average percent error at each temperature step for the distributed sensor................................. 7 


\section{INTRODUCTION}

A regenerated fiber Bragg grating (FBG) optical fiber sensor and a distributed optical fiber sensor were evaluated in a tube furnace in the High Temperature Test Lab (HTTL) to determine the accuracy of the temperature measurements at each of the gratings and at various locations along the length of the distributed sensor. These sensors were tested as a part of the Advanced Instrumentation for Transient Testing project as research to determine the feasibility of using fiber optics as instrumentation for the TREAT project. The Bragg grating sensor as well as the associated readout system was provided through an international collaboration with the French Commissariat à l'énergie atomique et aux énergies alternatives (CEA). The sensor had 10 inscribed regenerated Bragg gratings in the sensing region, labeled \#0 through \#9, each grating was spaced 1 centimeter apart. The fiber that the gratings were inscribed into was single mode silica $\left(\mathrm{SiO}_{2}\right)$ optical fiber. The distributed sensor was provided through a commercial partner, Luna innovations, and interrogated with the Luna Optical Backscatter Reflectometer (OBR). The sensor consisted of an unaltered single mode silica optical fiber in a protective package. The Bragg sensor was tested up to $750^{\circ} \mathrm{C}$ and the distributed sensor was tested to $550^{\circ} \mathrm{C}$. Table 1 shows the temperature steps used for each of the sensors.

Table 1. Temperature steps for the fiber Bragg grating and distributed sensors.

\begin{tabular}{|c|c|c|c|}
\hline \multicolumn{2}{|c|}{ Bragg Grating } & \multicolumn{2}{|c|}{ Distributed } \\
\hline Temperature $\left({ }^{\circ} \mathrm{C}\right)$ & Time & Temperature $\left({ }^{\circ} \mathrm{C}\right)$ & Time \\
\hline 100 & $30 \mathrm{~min}$ & 100 & $30 \mathrm{~min}$ \\
\hline 200 & $30 \mathrm{~min}$ & 200 & $30 \mathrm{~min}$ \\
\hline 300 & $30 \mathrm{~min}$ & 300 & $30 \mathrm{~min}$ \\
\hline 400 & $30 \mathrm{~min}$ & 400 & $30 \mathrm{~min}$ \\
\hline 500 & $30 \mathrm{~min}$ & 500 & $30 \mathrm{~min}$ \\
\hline 550 & $30 \mathrm{~min}$ & 550 & $30 \mathrm{~min}$ \\
\hline 650 & $30 \mathrm{~min}$ & 350 & $30 \mathrm{~min}$ \\
\hline 750 & $30 \mathrm{~min}$ & & \\
\hline 400 & $30 \mathrm{~min}$ & & \\
\hline
\end{tabular}

A K-type thermocouple (TC) was used to measure the temperature at the locations of the Bragg gratings on and at various locations on the distributed sensor. The sensors were heated in a gold reflected Trans Temp tube furnace by Thermcraft that was controlled with the Thermcraft Express-line controller. The sensors were heated in an argon environment to prevent any oxidation. A quartz tube was placed in the center of the tube furnace and argon was flown through the tube continuously. The sensor was placed in one side of the tube through a Swagelok fitting and the thermocouple was placed in the other side of the tube through a second Swagelok fitting. Figure 1 shows the tube furnace that was used to heat the sensors. 


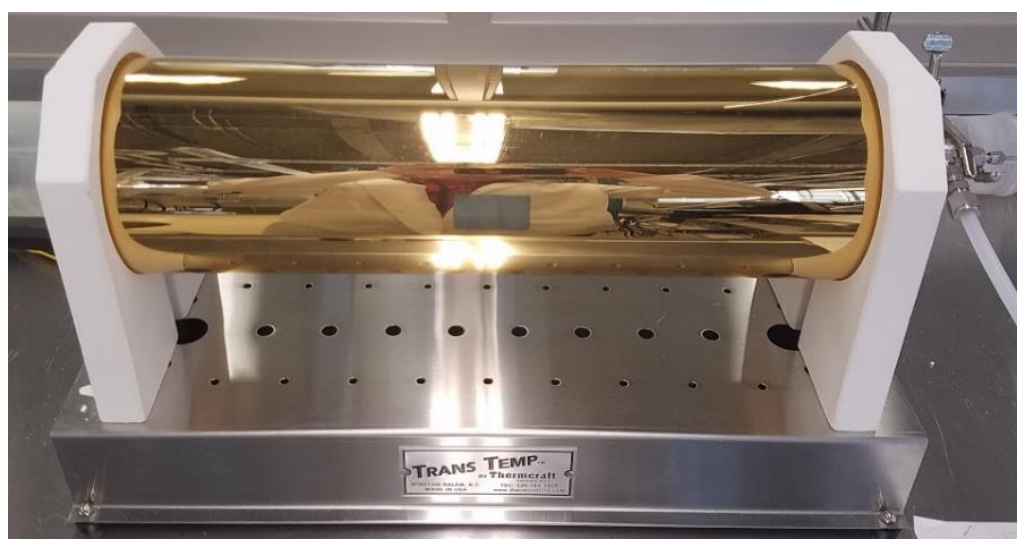

Figure 1.Trans Temp tube furnace by Thermcraft.

\subsection{Fiber Bragg Grating Sensor}

FBG sensors measure the shift in the Bragg wavelength of the grating as temperature changes. The shift is measured at each grating allowing for multiple measurements along the length of the fiber. Longterm use of Bragg gratings at temperatures beyond $400-500^{\circ} \mathrm{C}$ leads to drift and reduced reflectivity resulting in failure of the gratings. Type-I photowritten FBGs are multiplexed into a standard single mode silica optical fiber and regenerated through a high-temperature annealing process. Regenerated type-I FBGs have been shown to withstand temperatures up to $900^{\circ} \mathrm{C}$ and potentially up to $1295^{\circ} \mathrm{C}$ [1]. Figure 2 shows a scan of the fiber Bragg sensor that was evaluated at HTTL, each of the 10 FBGs is of a different wavelength and is calibrated separately to a polynomial fit that was provided with the sensor. 


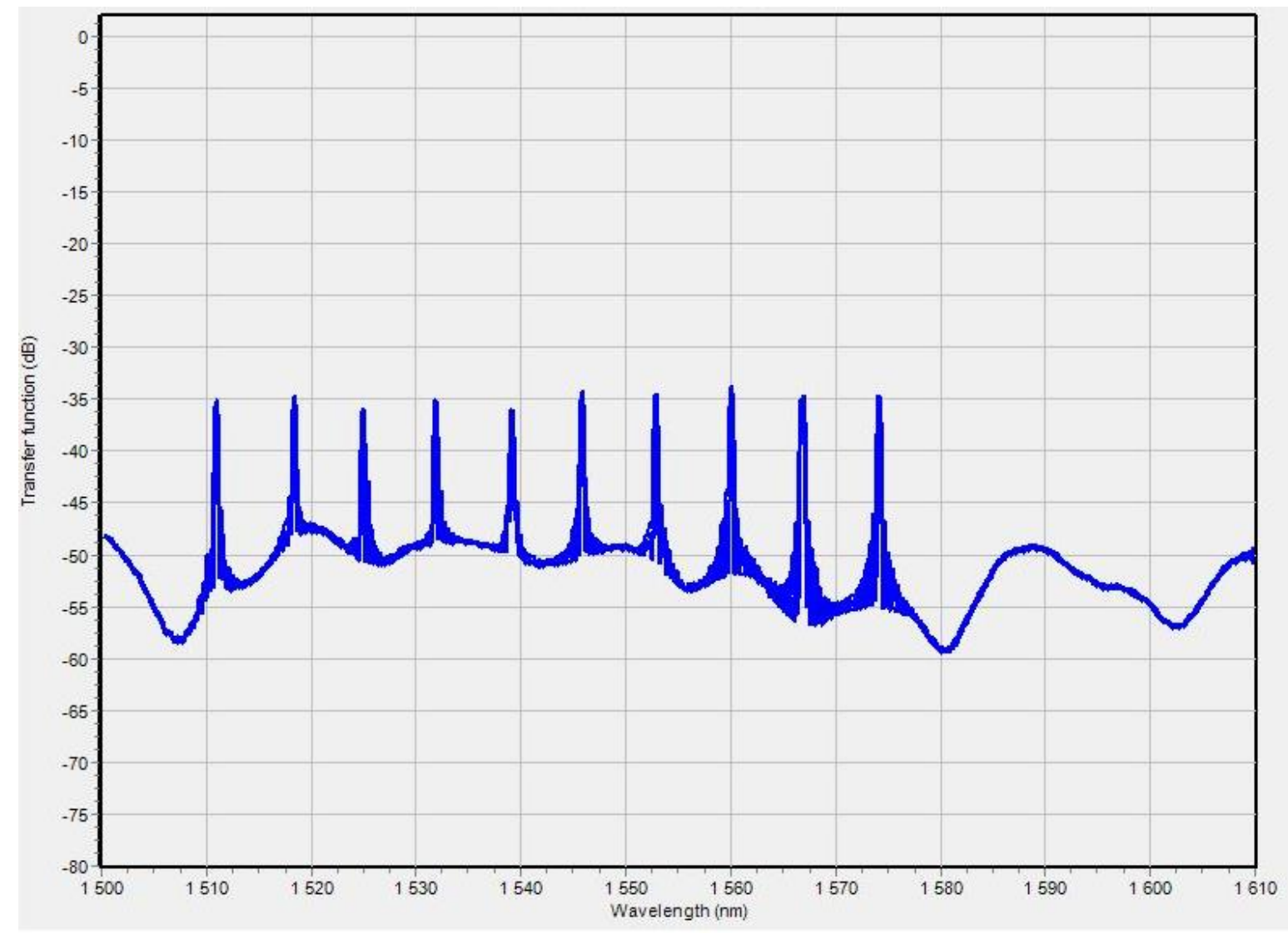

Figure 2. Fiber Bragg sensor scan.

The Bragg sensor was connected to a Yenista Optics CT400 all-band optical component tester and a Yenista Optics Tunics-T100S HP tunable laser that was provided by CEA. The shift in Bragg wavelength for each of the gratings as temperature was increased was fit to temperature using polynomial calibration curves. The calibration curves can be seen in Appendix A, Figure A.1. Each FBG has a separate calibration curve that was provided with the sensor.

\subsection{Distributed Sensor}

The distributed optical fiber sensor is an unaltered single mode silica fiber that uses the natural defects and density fluctuations in the amorphous glass. Swept wavelength interferometry (SWI) is used to measure the Rayleigh backscatter as a function of the length of the optical fiber. The Rayleigh backscatter is caused by the random defects and density fluctuations in the fiber. For any given fiber the Rayleigh backscatter signal is random but constant, up to certain temperatures, and the thermal expansion in the fiber causes a shift in the reflected spectrum of the fiber. This shift can be calibrated to an initial reference scan of that fiber creating a distributed temperature sensor [2]. The distributed sensor that was tested in HTTL was an unaltered single mode silica optical fiber. Figure 3 shows a scan of the sensor. 


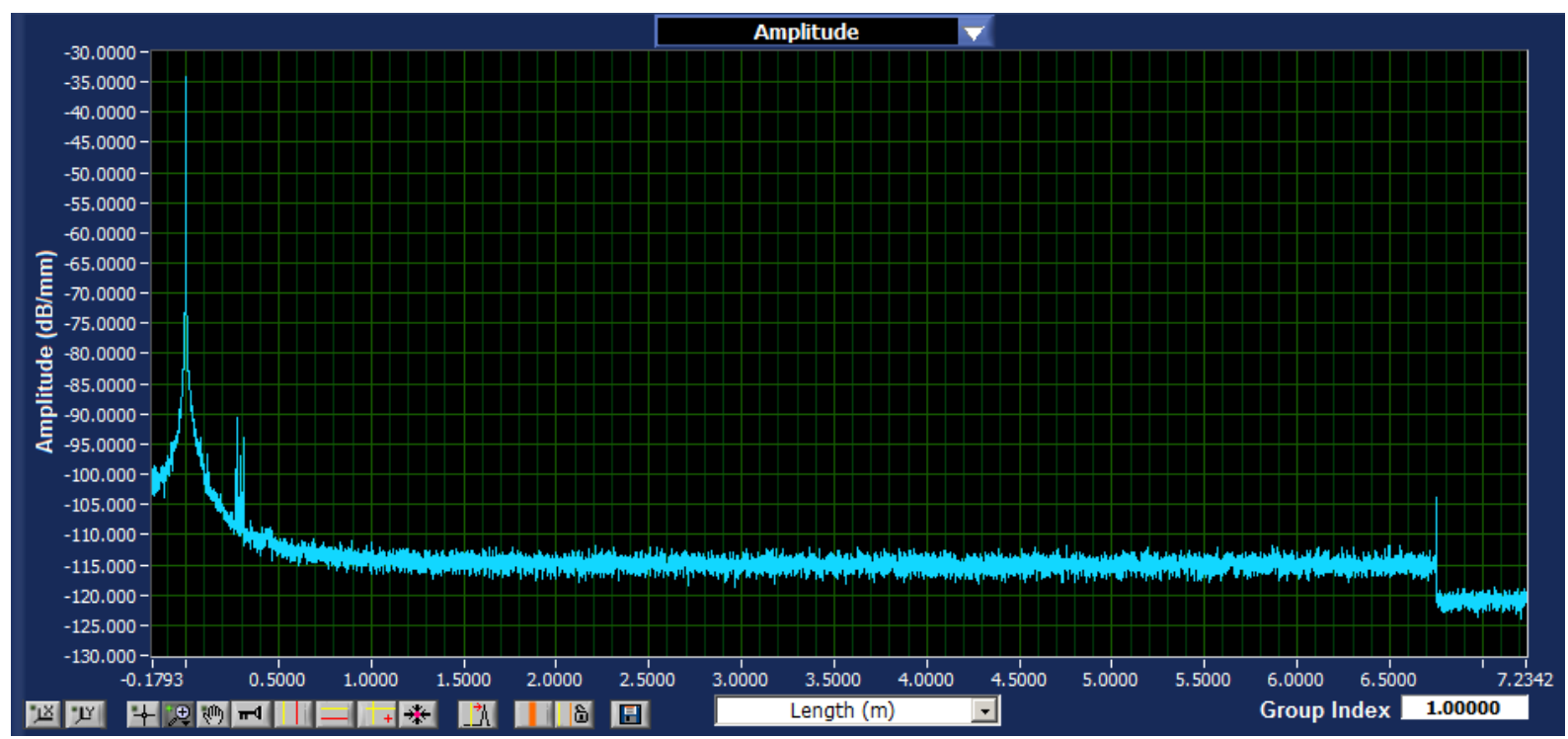

Figure 3. Scan of the distributed sensor.

There are no gratings in the fiber and the scan in Figure 3 shows that there are no major reflections along the length of the fiber. The Rayleigh backscatter profile of the sensor was measured at room temperature to serve as the reference scan. The scans of the sensor while it was being heated were referenced back to an initial scan at room temperature. The spectral shift was calibrated with a polynomial fit and measures the relative temperature change. The calibration curve fit can be seen in Appendix a, Figure A.2.

\section{Results}

Both of the optical fiber sensors produced more accurate measurements at high temperatures. The Bragg sensor measurement drifted through successive heating cycles making the reading less accurate. The distributed sensor did not drift however there were measurements at $500^{\circ} \mathrm{C}$ and $550^{\circ} \mathrm{C}$ that produced bad data points.

\subsection{Bragg Sensor Response}

The Bragg sensor was heated for 11 cycles, one cycle for each FBG so that a thermocouple (TC) could be placed at the location of the grating and an extra cycle to compare the first and last cycles on the same FBG. Figures 4 and 5 show the response of FBG \#9 in the first heating cycle and in the eleventh heating cycle. The figures show that the sensor measurement drifted from the first cycle to the last cycle. Figure 5 shows a hold at $400^{\circ} \mathrm{C}$ during cooling because it was added after the experiment began to see how the sensor responded to cooling. 


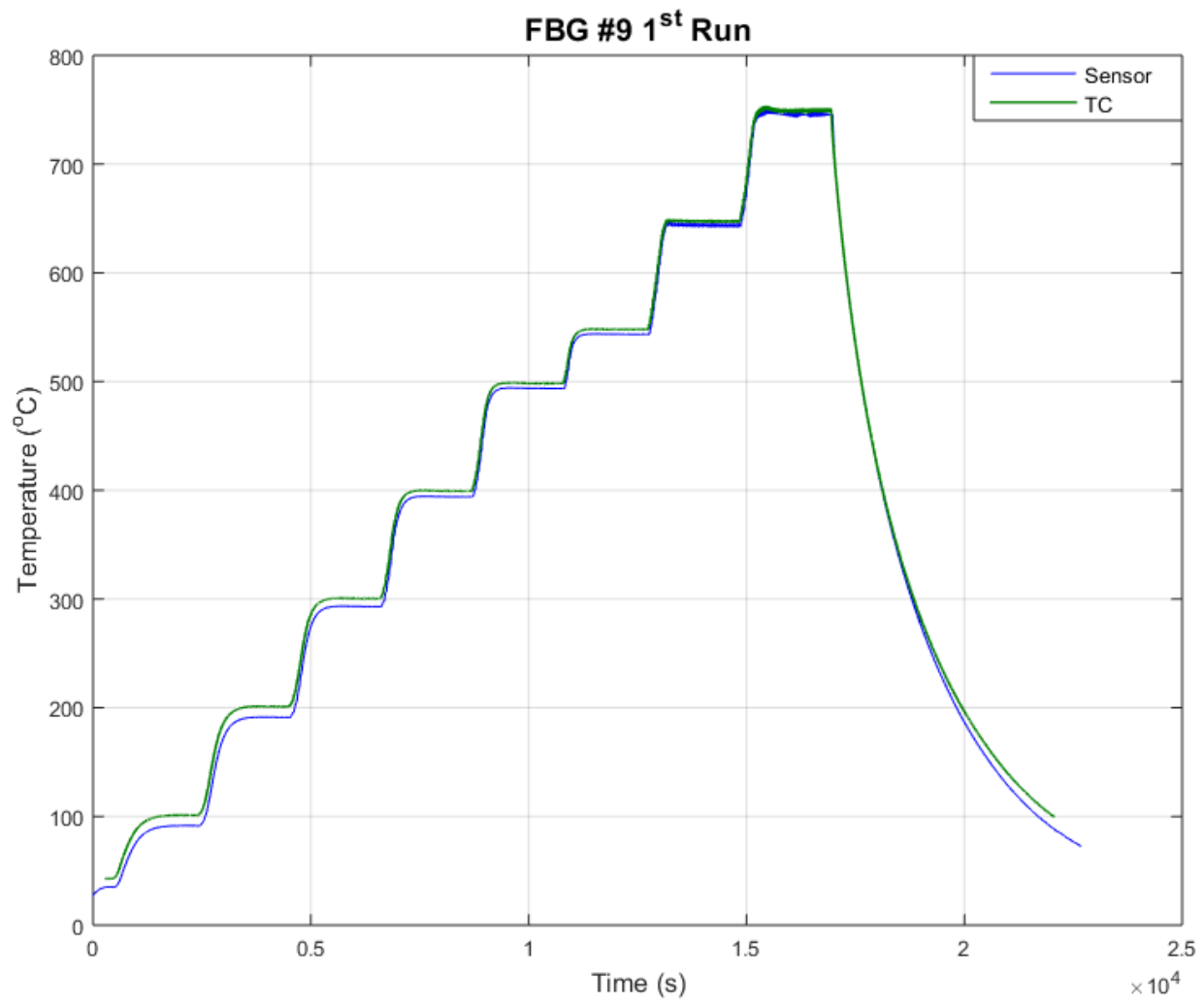

Figure 4. FBG \#9 sensor response, 1 st cycle.

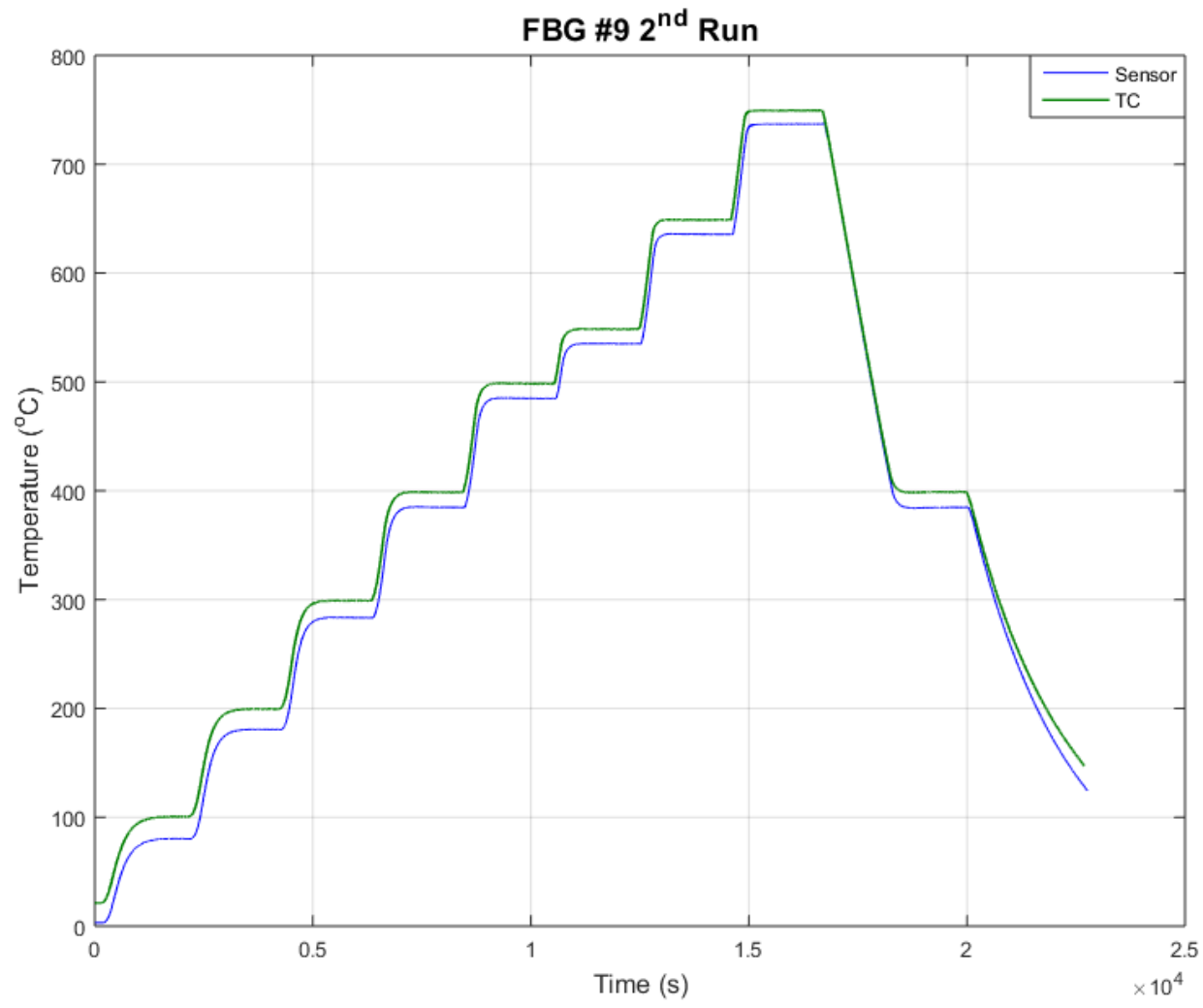

Figure 5. FBG \#9 sensor response, 2nd cycle. 
Tables 2 and 3 summarize the average temperatures at each step for the thermocouple and FBG \#9 for both of the runs. There was approximately a 10 degree drift between the first run and the last run, this is shown on Figure 6 on the next page. The other 9 Bragg gratings behaved similarly and showed about a 10 degree drift over the course of the experiment. All 10 of the gratings were more accurate at the higher temperatures, it was advised that the calibration curve was not accurate until approximately $300^{\circ} \mathrm{C}$. This can been seen from the error between the thermocouple and the FBG with the highest errors being the $100^{\circ} \mathrm{C}$ and $200^{\circ} \mathrm{C}$ temperature steps.

Table 2. Average Temperatures for FBG \#9 during the 1st run.

\begin{tabular}{|c|c|c|c|}
\hline \multicolumn{4}{|c|}{ FBG \#9 Run 1 } \\
\hline $\begin{array}{c}\text { Temperature } \\
\text { Step }\left({ }^{\circ} \mathrm{C}\right)\end{array}$ & $\begin{array}{c}\text { TC Temperature } \\
\left({ }^{\circ} \mathrm{C}\right)\end{array}$ & $\begin{array}{c}\text { FBG Temperature } \\
\left({ }^{\circ} \mathrm{C}\right)\end{array}$ & \% Error \\
\hline 100 & 100.38 & 91.43 & 8.92 \\
\hline 200 & 200.97 & 191.29 & 4.82 \\
\hline 300 & 300.41 & 293.2 & 2.4 \\
\hline 400 & 399.49 & 394.14 & 1.34 \\
\hline 500 & 498.4 & 493.82 & 0.92 \\
\hline 550 & 547.98 & 543.62 & 0.8 \\
\hline 650 & 647.47 & 643.87 & 0.56 \\
\hline 750 & 749.19 & 746.17 & 0.4 \\
\hline 400 & N/A & N/A & N/A \\
\hline
\end{tabular}

Table 3. Average temperatures for FBG \#9 during the 2nd run.

\begin{tabular}{|c|c|c|c|}
\hline \multicolumn{4}{|c|}{ FBG \#9 Run 2 } \\
\hline $\begin{array}{c}\text { Temperature } \\
\text { Step }\left({ }^{\circ} \mathrm{C}\right)\end{array}$ & $\begin{array}{c}\text { TC Temperature } \\
\left({ }^{\circ} \mathrm{C}\right)\end{array}$ & $\begin{array}{c}\text { FBG Temperature } \\
\left({ }^{\circ} \mathrm{C}\right)\end{array}$ & \% Error \\
\hline 100 & 100.49 & 80.25 & 20.14 \\
\hline 200 & 199.51 & 180.63 & 9.46 \\
\hline 300 & 299.07 & 283.44 & 5.23 \\
\hline 400 & 398.67 & 384.89 & 3.46 \\
\hline 500 & 498.47 & 484.88 & 2.73 \\
\hline 550 & 548.65 & 535.1 & 2.47 \\
\hline 650 & 648.9 & 635.76 & 2.02 \\
\hline 750 & 749.32 & 736.88 & 1.66 \\
\hline 400 & 398.77 & 384.55 & 3.57 \\
\hline
\end{tabular}




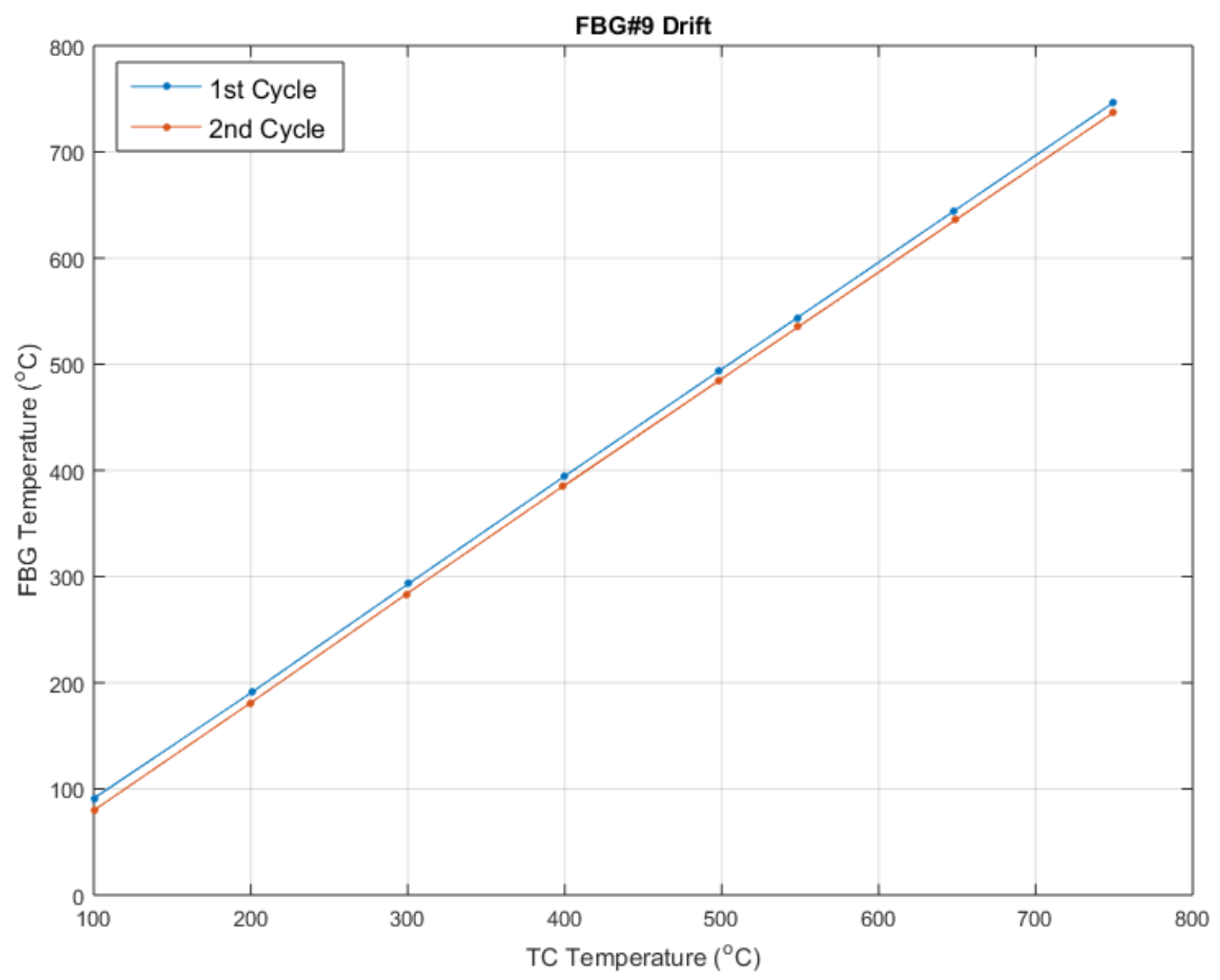

Figure 6. Sensor drift between the 1 st cycle and the 2 nd cycle of FBG \#9.

\subsection{Distributed Sensor Response}

The distributed sensor was tested up to $550^{\circ} \mathrm{C}$ and did not show any evidence of drift. Figure 7 shows the temperature profile in the furnace along the length of the sensor for temperature steps up to $400^{\circ} \mathrm{C}$ and the cooling step at $350^{\circ} \mathrm{C}$. The cooling step at $350^{\circ} \mathrm{C}$ produced much less accurate measurements. This may indicate that when the fiber cools, the density fluctuations and defects may not return to the reference profile. Temperature steps $500^{\circ} \mathrm{C}$ and $550^{\circ} \mathrm{C}$ are shown on a separate graph for clarity (See Figure 8). 


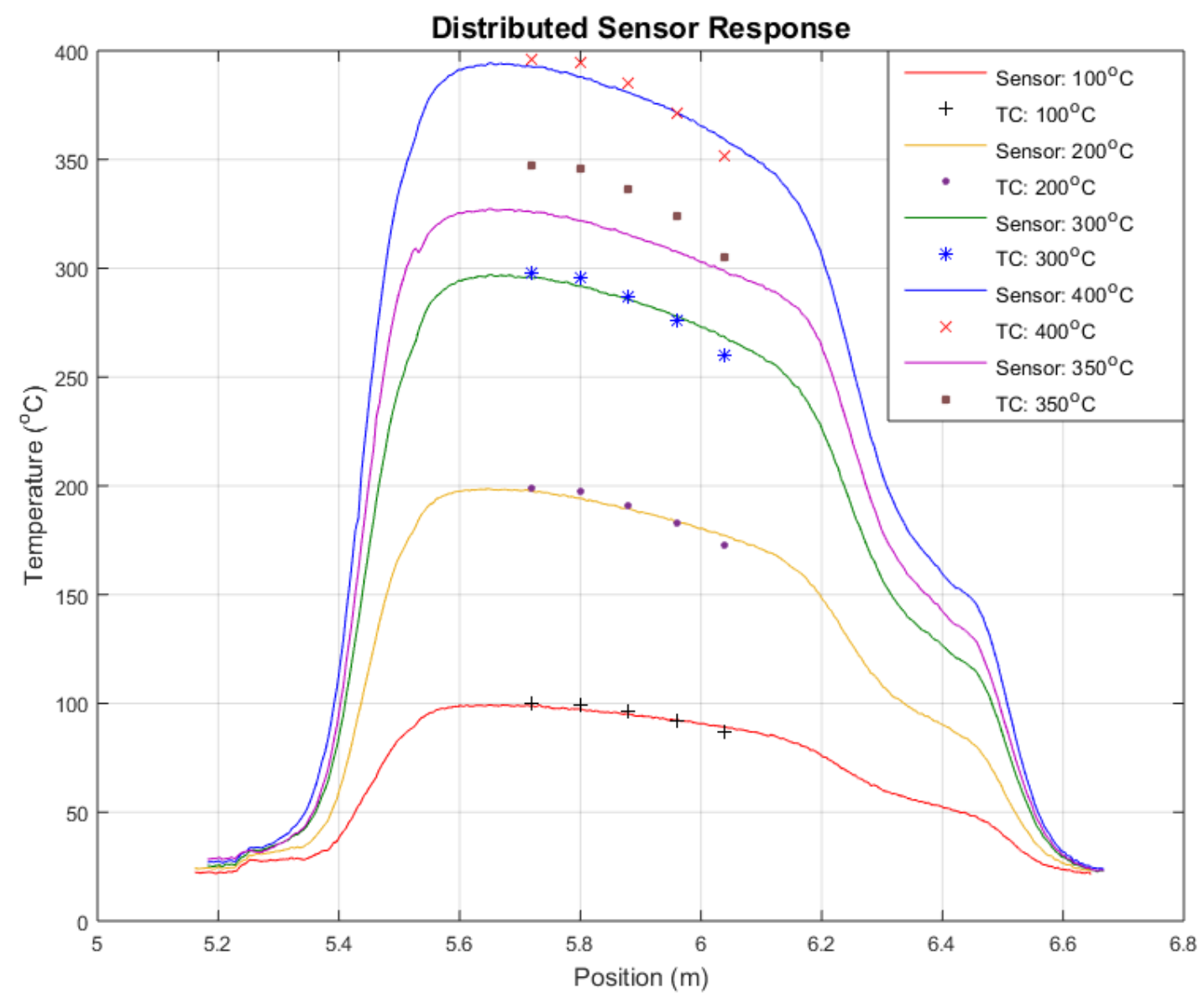

Figure 7. Distributed sensor response for temperature steps up to $400^{\circ} \mathrm{C}$.

Table 4 summarizes the average error between the thermocouple measurement and the sensor measurement at all 5 locations for each temperature step. The largest error was during the $350^{\circ} \mathrm{C}$ hold at $6.82 \%$ and the largest error for the increasing temperature steps was $3.09 \%$.

Table 4. Average percent error at each temperature step for the distributed sensor.

\begin{tabular}{|c|c|}
\hline $\begin{array}{c}\text { Temperature } \\
\text { Step }\left({ }^{\circ} \mathrm{C}\right)\end{array}$ & $\begin{array}{c}\text { Average \% } \\
\text { Error }\end{array}$ \\
\hline 100 & 1.09 \\
\hline 200 & 1.22 \\
\hline 300 & 1.32 \\
\hline 400 & 1.19 \\
\hline 500 & 0.75 \\
\hline 550 & 0.93 \\
\hline 350 & 5.29 \\
\hline
\end{tabular}

At the temperature steps of $500^{\circ} \mathrm{C}$ and $550^{\circ} \mathrm{C}$ there were some abnormalities in the spectral shift measurement, these can be seen in the temperature profile in Figure 8. This could be due to density 
changes that are large enough that the scan cannot be referenced back to the original scan or defect migrations. This could also be caused from a noisy backscatter signal. Figure 3 shows that there is a large spike in attenuation at 0 meters, this is the connection of the sensor to the front panel of the OBR interrogator. This resulted in a lower backscatter signal and a smaller separation between the signal from the fiber and the noise floor. The majority of the sensor still produced measurements however the rest of the sensor may fail in a longer run at high temperatures.

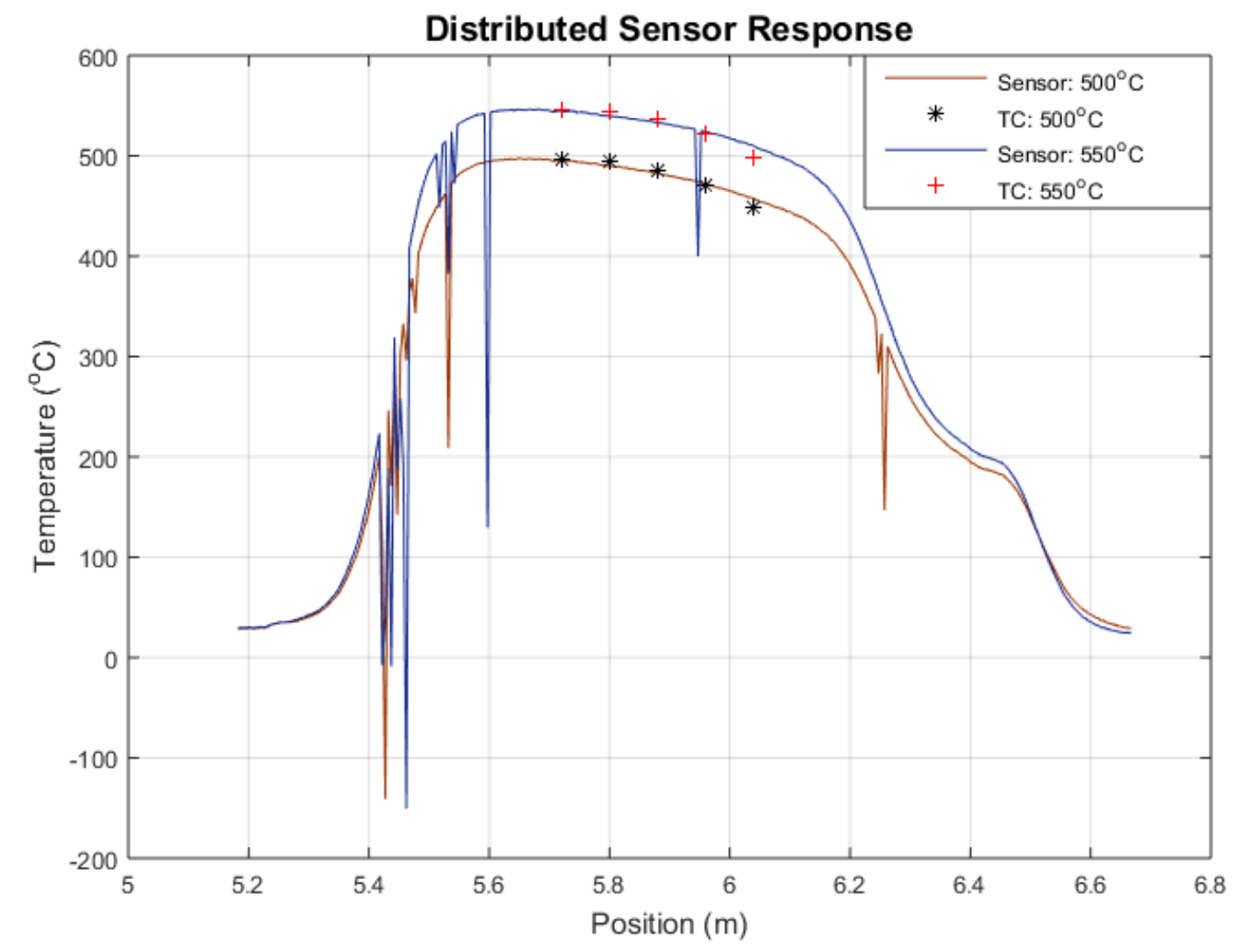

Figure 8. Distributed sensor response for temperature steps $500^{\circ} \mathrm{C}$ and $550^{\circ} \mathrm{C}$.

\section{Conclusion and Future Work}

Further experiments should be conducted on the Bragg sensor to evaluate if the drift observed in this experiment continues or stabilizes. The distributed sensor should be tested at temperatures around $500^{\circ} \mathrm{C}$ for longer periods of time to evaluate if defect migration renders the scan incompatible to the reference scan. The Bragg sensor drifted approximately $-10^{\circ} \mathrm{C}$ over the course of the heating cycles and performed better at higher temperatures. The distributed sensor produced more accurate measurements with increasing temperature but had large differences from the thermocouple, $\sim 5 \%$, when the sensor was cooled instead of heated. The sensor also produced some bad data points at $500^{\circ} \mathrm{C}$ and above.

\section{References}

1. G. Laffont, R. Cotillard, P. Ferdinand, "Multiplexed regenerated fiber Bragg gratings for hightemperature measurement,” Meas. Sci. Technol., 24 No. 9, 2013, 094010. 
2. D. K. Gifford, B. J. Soller, M. S. Wolfe, and M. E. Froggatt, "Distributed fiber-optic temperature sensing using Rayleigh backscatter,"inProc. ECOC 2005, Sep. 2005, pp. 005-005, We4

\section{Appendix A}

\section{Calibration Curves}

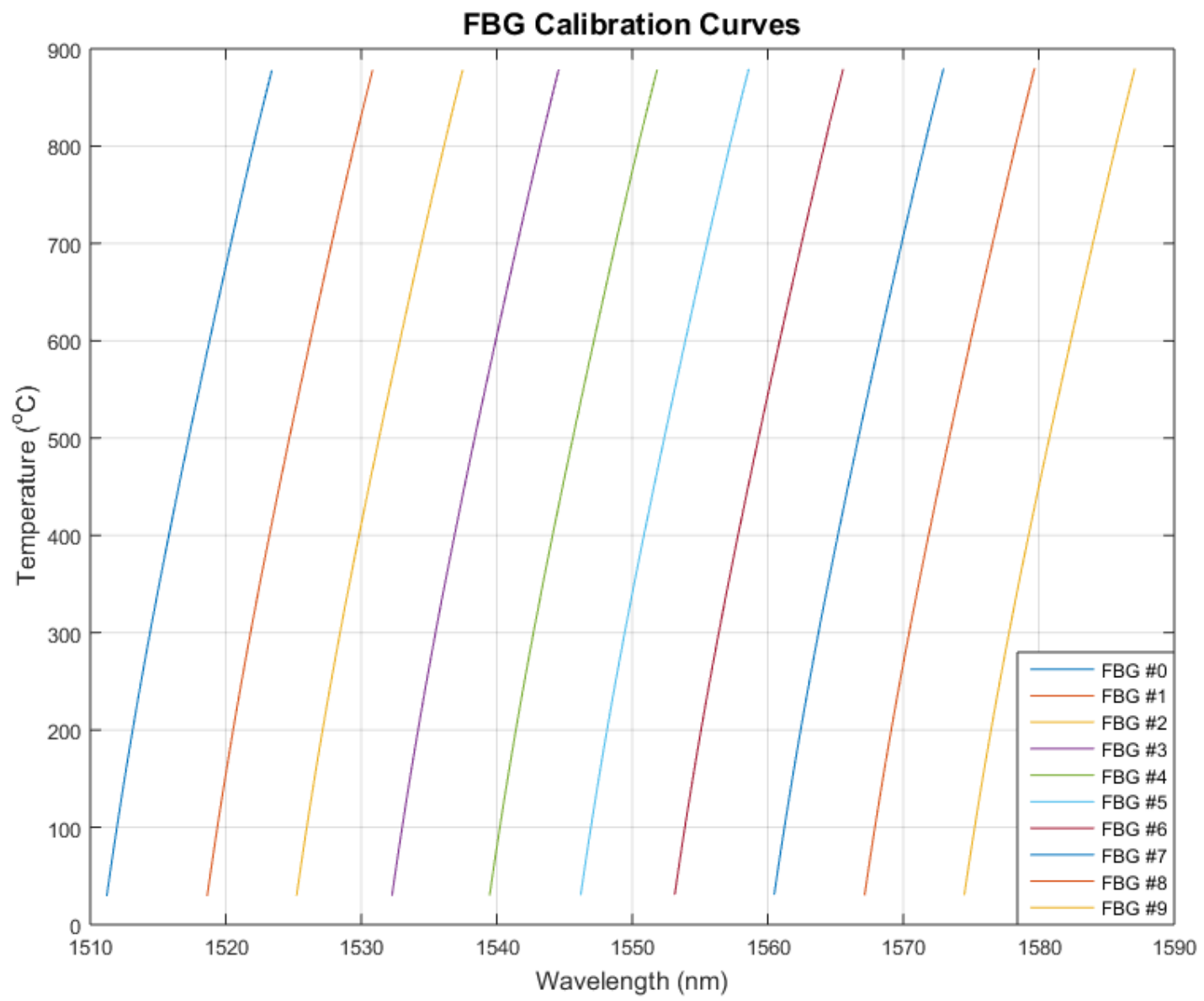

Figure A.1. Provided calibration curves for the fiber Bragg grating sensor. 


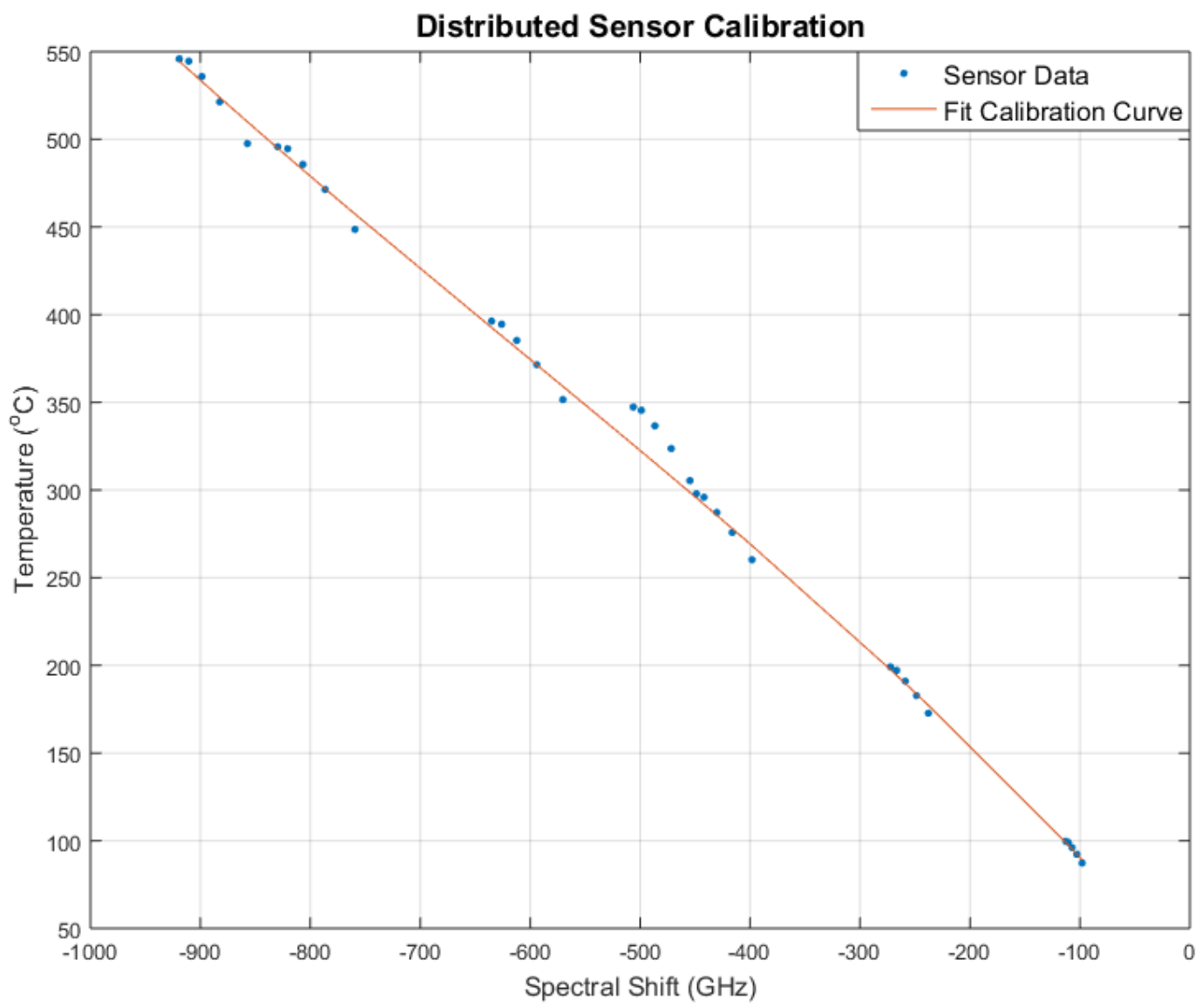

Figure A.2. Fit calibration curve for the distributed sensor. $R^{2}=0.9992$ 